\title{
COLISÃO DE DIREITOS FUNDAMENTAIS, PONDERAÇÃO E PROPORCIONALIDADE NA VISÃO DE ROBERT ALEXY
}

\author{
Diego Brito Cardoso ${ }^{234}$
}

Recebido em: 28/07/2016

Aprovado em: 02/08/2016

\begin{abstract}
RESUMO
O presente artigo parte da problemática relacionada à colisão entre direitos fundamentais, a qual tornou-se de estudo obrigatório no Brasil após a promulgação da Constituição Federal de 1988. Com efeito, a nossa Carta Magna plasmou diversos direitos fundamentais em seu corpo, tornando difícil a vida do seu intérprete em face das constantes situações nas quais dois ou mais direitos entram em conflito. Neste contexto, o conceito de princípio desenvolvido por Robert Alexy, bem como a sua teoria segundo a qual a colisão entre direitos fundamentais, quando estruturados como princípios, deve ser solucionada com a aplicação da técnica da ponderação através do princípio da proporcionalidade, ganham destaque no cenário jurídico nacional. Não obstante, nota-se que a aplicação de sua teoria por parte da Poder Judiciário não raramente gera decisionismos e insegurança jurídica, motivando a elaboração deste artigo para contribuir para um melhor entendimento das lições de Robert Alexy e, consequentemente, uma maior clareza na aplicação da ponderação e da proporcionalidade.
\end{abstract}

Palavras-chave: Direitos fundamentais. Colisão. Ponderação. Proporcionalidade.

\section{INTRODUÇÃO}

A Constituição Federal de 1988 positivou diversos direitos fundamentais em seu texto, caracterizando-se como um ambioso projeto para transformação da sociedade brasileira.

Com efeito, o Brasil estava finalmente saindo de mais de 20 (vinte) anos de ditadura, razão pela qual a Assembléia Constituinte se esforçou em prever na Carta Magna direitos fundamentais de toda sorte, retirando do alcance do legislador ordinário a possibilidade de supressão ou diminuição de tais garantias. Educação e saúde para todos, meio ambiente equilibrado, cultura, desporto, assistência social, previdência, proteção da criança, adolescente,

234 Procurador do Estado junto à Procuradoria Geral do Estado de São Paulo. Endereço eletrônico: di.brito.cardoso@gmail.com. 
jovem e idoso, acesso à justiça. Todos esses temas foram contemplados de alguma forma pela Constituição Federal de 1988.

Conjuntamente a este cenário adveio o fortalecimento do Poder Judiciário, principalmente com a previsão do princípio da inafastabilidade da jurisdição ou do acesso à justiça ${ }^{235}$, com o alargamento do rol de legitimados para ingressar com ações de controle abstrato de constitucionalidade perante o Supremo Tribunal Federal ${ }^{236}$, bem como com a possibilidade de qualquer juiz realizar o controle concreto de constitucionalidade de qualquer norma jurídica.

Com efeito, a enorme gama de direitos fundamentais previstos na Carta Magna de 1988, aliada a um Poder Judiciário mais forte, contribuiu para uma crescente judicialização de direitos. Ocorre que, em diversas situações cotidianas da vida, a aplicação dos direitos fundamentais podem resultar em colisão ou conflito entre eles, gerando uma dificuldade, ao intérprete, em relação a qual direito deva prevalecer no caso concreto.

Neste panorama, a teoria do jurista alemão Robert Alexy defende, com base na jurisprudência alemã, o uso da técnica da ponderação e do princípio da proporcionalidade como soluções para o problema da colisão entre direitos fundamentais estruturados como princípios, tendo sido amplamente incorporada no Brasil pela doutrina e pelo Poder Judiciário.

$235 \mathrm{O}$ artigo $5^{\circ}$, inciso XXV da Constituição Brasileira consagra o princípio do acesso à justiça ou da inafastabilidade da jurisdição, ao prever que "a lei não excluirá da apreciação do Poder Judiciário lesão ou ameaça a direito".

O artigo VIII da Declaração Universal dos Direitos Humanos, bem como o item 1 do artigo 8 da Convenção Americana sobre Direitos Humanos (Pacto de São José da Costa Rica), preveem garantias semelhantes, respectivamente:

Art. VIII - Todo ser humano tem direito a receber dos tribunais nacionais competentes remédio efetivo para os atos que violem os direitos fundamentais que lhe sejam reconhecidos pela constituição ou pela lei.

Art. $8^{\circ}$, item 1 - Toda pessoa tem direito a ser ouvida, com as devidas garantias e dentro de um prazo razoável, por um juiz ou tribunal competente, independente e imparcial, estabelecido anteriormente por lei, na apuração de qualquer acusação penal formulada contra ela, ou para que se determinem seus direitos ou obrigações de natureza civil, trabalhista, fiscal ou de qualquer outra natureza.

${ }^{236}$ A redação inicialmente trazida no texto da Constituição Federal de 1988 era a seguinte:

Art. 103. Podem propor a ação de inconstitucionalidade:

I - o Presidente da República;

II - a Mesa do Senado Federal;

III - a Mesa da Câmara dos Deputados;

IV - a Mesa de Assembléia Legislativa;

V - o Governador de Estado;

VI - o Procurador-Geral da República;

VII - o Conselho Federal da Ordem dos Advogados do Brasil;

VIII - partido político com representação no Congresso Nacional;

IX - confederação sindical ou entidade de classe de âmbito nacional.

Por outro lado, relembre-se que, na vigência da Emenda Constitucional 01/69, apenas o Procurador-Geral da República possuia legitimidade para tal fim, in verbis:

Art. 119. Compete ao Supremo Tribunal Federal:

l) a representação do Procurador-Geral da República, por inconstitucionalidade de lei ou ato normativo federal ou estadual. 
Não obstante, constata-se que a aplicação de tais postulados passou a servir muitas vezes para justificar meros subjetivismos do intérprete, carecendo de maior rigor científico. Com efeito, não são poucos os julgados que utilizam-se do princípio da proporcionalidade apenas para justificar uma escolha pessoal por parte do julgador, sem a demonstração completa do raciocínio aplicado.

Sendo assim, a elaboração do presente artigo pretende contribuir para o debate acerca da correta aplicação das teorias da ponderação e da proporcionalidade de Robert Alexy, sem qualquer pretensão de esgotar o assunto.

\title{
2 A ESTRUTURA DOS DIREITOS FUNDAMENTAIS
}

Os direitos fundamentais são assim considerados por serem considerados como inerentes à condição humana. Conforme os ensinamentos de Vidal Serrano Nunes Júnior, direitos fundamentais podem ser entendidos

\begin{abstract}
como o sistema aberto de princípios e regras que, ora conferindo direitos subjetivos a seus destinatários, ora conformando a forma de ser e de atuar do Estado que os reconhece, tem por objetivo a proteção do ser humano em suas diversas dimensões, a saber: em sua liberdade (direitos e garantias individuais), em suas necessidades (direitos sociais, econômicos e culturais) e em relação à sua preservação (solidariedade). ${ }^{237}$
\end{abstract}

Utilizando-se dos ensinamentos de Peter Härbele ${ }^{238}$ e corroborando o conceito de Vidal Serrano Nunes Júnior, é certo que os direitos fundamentais funcionam como um sistema, uma vez que suas normas encontram-se em permanente interação e, consequentemente, em constante colisão. Segundo Härbele, tal sistema possui a característica de ser aberto, já que tais normas devem ser obrigatoriamente interpretadas de acordo com o contexto político, econômico e social vigente. Com efeito, é essa abertura que promove a integração entre a norma e a realidade, permitindo a chamada mutação constitucional, isto é, a alteração do significado da norma sem a correspondente mudança do texto normativo.

Devido à sua importância, é condição para a configuração de um verdadeiro Estado Democrático de Direito que os direitos fundamentais possuam força vinculante, obrigando tanto

\footnotetext{
${ }^{237}$ NUNES JUNIOR, Vidal Serrano. A cidadania social na Constituição de 1988. - Estratégias de Positivação e Exigibilidade Judicial dos Direitos Sociais. São Paulo: Editora Verbatim, 2009. p. 15.

${ }^{238}$ HÄRBELE, Peter. Hermenêutica Constitucional - A Sociedade Aberta dos Intérpretes da Constituição: contribuição para a interpretação pluralista e procedimental da Constituição. Tradução e apresentação de Gilmar Ferreira Mendes. Porto Alegre: Editora Sergio Antonio Fabris, 1997.
} 
o Estado quanto os particulares a respeitá-los. Não obstante, não podemos olvidar que, para que tais garantias possuam tal força, é imprescindível que todas normas de direitos fundamentais possam ser justiciáveis, ou seja, que sua efetivação possa ser verificada pelo Poder Judiciário. Neste cenário, de rigor reconhecer o princípio do acesso à justiça, bem como o fortalecimento do Poder Judiciário, como essenciais para o contínuo desenvolvimento de qualquer sociedade.

Exposto um conceito doutrinário de direitos fundamentais, é importante mencionar que tais direitos podem ser definidos em duas dimensões. Em sua dimensão objetiva, os direitos fundamentais demonstram a forma de organização e atuação do Estado. ${ }^{239}$ Já em sua dimensão subjetiva, direitos fundamentais podem ser definidos como direitos a uma prestação (direitos subjetivos), ou seja, são situações jurídicas onde o titular tem a prerrogativa de exigir de alguém determinada conduta. Logo, se de um lado existe um direito a uma prestação, do outro deve exigir um dever de prestação. Assim sendo, é certo que os direitos fundamentais podem se situar tanto no plano das relações entre o Estado e os particulares, quanto apenas entre particulares.

Como cediço, as normas jurídicas podem se estruturar em forma de regras ou de princípios, sendo diversas as formas de diferenciá-los.

Com base no critério de fundamentalidade da norma, princípios podem ser entendidos como sendo as normas mais fundamentais do sistema, enquanto as regras seriam a concretização de tais princípios. Já utilizando-se do critério da generalidade, princípios seriam as normas com grau de generalidade mais elevada, enquanto as regras seriam as normas com grau de generalidade mais baixo.

Humberto Ávila, por sua vez, defende que regras e princípios diferenciam-se entre si em relação ao grau de abstração correspondente, sendo os princípios mais abstratos do que as regras. De acordo com seu entendimento,

pode-se definir os princípios como normas que estabelecem diretamente fins, para cuja concretização estabelecem com menor exatidão qual o comportamento devido (menor grau de determinação da ordem e maior generalidade dos destinatários), e por isso dependem mais intensamente da sua relação com outras normas e de atos institucionalmente legitimados de interpretação para a determinação da conduta devida. $^{240}$

${ }^{239}$ GUERRA FILHO, Willis Santiago. Processo Constitucional e Direitos Fundamentais. 4. ed. São Paulo: RCS, 2007. p. 45.

240 ÁVILA, Humberto. A distinção entre princípios e regras e a redefinição do dever de proporcionalidade. Revista Diálogo Jurídico, Salvador, CAJ - Centro de Atualização Jurídica, v. I, nº. 4, julho, 2001. pg. 21. 
Por outro lado, as regras teriam a "função de eliminar ou reduzir problemas de coordenação, conhecimento, custos e controle do poder". ${ }^{241}$ Com efeito, por terem a função de descrever com maior clareza aquilo que é proibido, permitido ou mesmo obrigatório, as regras diminuem "a arbitrariedade e a incerteza, gerando ganhos em previsibilidade e em justiça para a maior parte dos casos" 242 .

Já Carsten Bäcker ${ }^{243}$ sustenta que a derrotabilidade deve ser o critério para distinguir regras e princípios. Segundo tal autor, derrotabilidade deve ser entendida como a capacidade de acomodar exceções. Assim, as regras seriam derrotáveis, já que sempre admitem exceções. A derrotabilidade das regras seria, portanto, decorrente da limitação humana de prever todas as circunstâncias relevantes incidentes no caso concreto, não sendo possível criar uma regra sem exceções. Por outro lado, princípios nunca seriam derrotáveis, já que, como mandamentos de otimização, seriam aplicados considerando todas as circunstâncias dadas, não podendo surgir nenhuma exceção em sua aplicação.

Para Ronald Dworkin ${ }^{244}$, a primeira diferença entre regras e princípios é em relação ao tipo de orientação que elas oferecem (dimensão de validade). As regras seriam aplicadas à maneira do tudo ou nada, isto é, ou as regras são válidas para o caso concreto e, por isso, aplicadas na sua integralidade, ou não são válidas, não sendo, portanto, aplicadas. Sendo assim, no caso de conflito entre duas regras, uma delas nunca poderá ser válida. Já os princípios não teriam essa dimensão de validade, e sim uma dimensão que as regras não possuem: a de peso ou importância. Desta forma, no caso de colisão entre princípios prevaleceria aquele com maior importância para aquele determinado caso concreto, sem que isso implicasse na invalidade do outro princípio, uma vez que em outros casos é possível que o princípio de mais importância seja outro.

Com base em tal distinção, Dowrkin sustenta que princípio é "um padrão que deve ser observado, não porque vá promover ou assegurar uma situação econômica, política ou social considerada desejável, mas porque é uma exigência de justiça ou equidade ou alguma outra dimensão de moralidade"245.

\footnotetext{
${ }^{241}$ ÁVILA, Humberto. "NEOCONSTITUCIONALISMO: ENTRE A "CIÊNCIA DO DIREITO" E O "DIREITO DA CIÊNCIA. Revista Eletrônica de Direito Do Estado (REDE), Salvador, Instituto Brasileiro de Direito Público, n. 17, janeiro/fevereiro/março, 2009. p. 4.

${ }^{242}$ Idem. Ibidem. p. 4.

${ }^{243}$ BÄCKER, Carsten. Regras, princípios e derrotabilidade. Revista Brasileira de Estudos Políticos n. ${ }^{\circ}$ 102, jan./jun. 2011. Belo Horizonte. p. 55-82.

${ }^{244}$ DWORKIN, Ronald. Levando os direitos a sério. Trad. Nelson Boeira. 3. ed. São Paulo: Editora WMF Martins Fontes, 2010. p. 39-46.

${ }^{245}$ DWORKIN, Ronald . Op. cit. p. 36.
} 
Robert Alexy, por sua vez, defende que a diferença entre regras e princípios é qualitativa, sendo tais categorias diferentes em relação à estrutura e à forma de aplicação. Em suas palavras, "o ponto decisivo na distinção entre regras e princípios é que princípios são normas que ordenam que algo seja realizado na maior medida possível dentro das possibilidades jurídicas e fáticas existentes". ${ }^{246}$

Por fim, Alexy ${ }^{247}$ defende que regras são normas que expressam deveres definitivos, ou seja, definem exatamente o que se deve fazer, devendo ser aplicadas sempre por subsunção. Regras só podem ser cumpridas ou não, sendo, portanto, mandamentos definitivos. Importante esclarecer que uma norma pode ser estruturada como uma regra, apesar de ser chamada de princípio. Ex: princípio da anterioridade tributária ${ }^{248}$. Os princípios, por sua vez, seriam mandamentos de otimização, ou seja, normas que obrigam que algo seja realizado na maior medida possível, de acordo com as possibilidades fáticas e jurídicas. Em outras palavras, princípios são normas que expressam deveres prima facie, cujo conteúdo definitivo somente é fixado após a análise das condições fáticas e jurídicas do caso concreto. Ex: o princípio da liberdade de expressão é um direito prima facie, já que ele constantemente entra em colisão com outros direitos, tais como a intimidade e a honra.

Conforme visto, existem diversas classificações e diferenças entre conceitos de regras e princípios. Não obstante, Virgilio Afonso da Silva não enxerga problema em tais distinções:

O que precisa ficar claro, como já salientei acima, é que não há que se falar em classificação mais ou menos adequada, ou, o que é pior, em classificação mais ou menos moderna. Classificações ou são coerentes e metodologicamente sólidas, ou são contraditórias, quando, por exemplo, são misturados diversos critérios distintos - e, por isso, pouco ou nada úteis. ${ }^{249}$

Desta forma, podemos concluir desde já que os direitos fundamentais podem constituir tanto regras quanto princípios. Porém, é certo que a maioria dos direitos fundamentais configuram-se como princípios.

Com efeito, a vantagem de utilizar-se de princípios é que tal modelo possibilita um meio-termo entre vinculação e flexibilidade, enquanto o modelo de regras implica em uma maior rigidez. Sendo assim, a vantagem de se estruturar direitos fundamentais na forma de

\footnotetext{
${ }^{246}$ ALEXY, Robert. Teoria dos Direitos Fundamentais. Trad. Virgílio Afonso da Silva. 2. ed. São Paulo: Editora Malheiros, 2014. p. 90.

${ }^{247}$ Idem. Ibidem. p. 90-108.

248 Art. 150. Sem prejuízo de outras garantias asseguradas ao contribuinte, é vedado à União, aos Estados, ao Distrito Federal e aos Municípios:

III - cobrar tributos:

b) no mesmo exercício financeiro em que haja sido publicada a lei que os instituiu ou aumentou.

${ }^{249}$ SILVA, Vírgilio Afonso da. Princípios e regras: mitos e equívocos acerca de uma distinção. Revista LatinoAmericana de Estudos Constitucionais I, 2003. p. 613.
} 
princípios é permitir o cumprimento da Constituição sem que se exija o impossível, como se fosse uma reserva do possível daquilo que o particular pode exigir razoavelmente do Estado e da sociedade.

Vistas as principais diferenças entre regras e princípios, passaremos ao estudo das soluções dadas por Robert Alexy para solucionar a colisão entre direitos fundamentais expressos na forma de regra e de princípios.

\section{COLISÃO ENTRE DIREITOS FUNDAMENTAIS E PONDERAÇÃO}

Segundo Robert Alexy ${ }^{250}$, as colisões de direitos fundamentais podem ser compreendidas estrita ou amplamente.

Colisões de direitos fundamentais em sentido estrito nascem sempre que o exercício ou a realização de determinado direito fundamental acarrete consequências negativas em relação a outro direito fundamental de outra pessoa. Ex: publicação de biografias não autorizadas caracteriza um conflito entre liberdade de expressão e direito de informação contra direitos da personalidade (privacidade, imagem e honra).

As colisões de direitos fundamentais em sentido estrito são divididas em colisões de direitos fundamentais idênticos e colisões de direitos fundamentais diferentes. As colisões de direitos fundamentais idênticos podem ser divididas em 4 (quatro) tipos:

a) quando os dois sujeitos são afetados em relação ao mesmo direito fundamental, estando ambos do mesmo lado. Ex: 2 (dois) grupos pedem para fazer uma manifestação no mesmo lugar e no mesmo horário (direito de reunião);

b) quando os dois sujeitos são afetados em relação ao mesmo direito fundamental, porém enquanto um exerce um direito de defesa liberal, o outro tenta exercer um direito de proteção. Ex: quando um policial mata um sequestrador para salvar o refém (direito à vida);

c) quando entram em conflito o lado positivo e o negativo do mesmo direito. Ex: direito à crença (direito de praticar ou não alguma crença);

d) quando entram em conflito o lado jurídico e o lado fático do mesmo direito. Ex: gratuidade da justiça (igualdade formal/jurídica e igualdade material/ fática).

Colisões de direitos fundamentais em sentido amplo, por sua vez, nascem sempre que o exercício ou a realização de determinado direito fundamental acarrete consequências negativas

${ }^{250}$ ALEXY, Robert. Colisão de direitos fundamentais e realização de direitos fundamentais no Estado de Direito Democrático. Revista de Direito Administrativo, Rio de Janeiro, v. 217, 2015. 
em relação a bens coletivos. A Ação de Descumprimento de Preceito Fundamental n. ${ }^{\circ} 101$ é um exemplo de colisão entre direitos fundamentias em sentido amplo. Tal ADPF analisou a constitucionalidade de atos normativos proibitivos da importação de pneus usados (Portarias do Departamento de Operações de Comércio Exterior - Decex e da Secretaria de Comércio Exterior - Secex, Resoluções do Conselho Nacional do Meio Ambiente - Conama e Decretos Federais), uma vez que diversas decisões judiciais estavam permitindo a importação de pneus usados de países que não faziam parte do MERCOSUL. Julgando parcialmente procedente o mérito desta ADPF, o Supremo Tribunal Federal declarou a constitucionalidade dos atos normativos supramencionados, privilegiando o meio ambiente equilibrado (bem coletivo) ao invés do direito ao exercício da livre iniciativa (direito fundamental) ${ }^{251}$.

Outro exemplo pode ser extraído do dever legal da indústria de cigarro colocar advertências sobre prejuízos à saúde em seus produtos ${ }^{252}$. Com efeito, tal determinação é uma intervenção na liberdade de exercício profissional dos produtores de cigarro (direito fundamental) feita com justificativa na proteção da população diante de riscos à saúde (saúde pública - bem coletivo).

Assim como Dworkin, Alexy entende que uma das soluções para a colisão entre regras é declarar uma delas inválida. Mas ele vai além, defendendo que é possível também a introdução de uma cláusula de exceção em determinada regra para que o conflito seja eliminado. Exemplificando sua posição, Alexy afirma o seguinte:

Um exemplo para um conflito entre regras que pode ser resolvido por meio da introdução de uma cláusula de exceção é aquele entre a proibição de sair da sala de aula antes que o sinal toque e o dever de deixar a sala se soar o alarme de incêndio. Se o sinal ainda não tiver sido tocado, mas o alarme de incêndio tiver soado, essas regras conduzem a juízos concretos de dever-ser contraditórios entre si. Esse conflito deve ser solucionado por meio da inclusão, na primeira regra, de uma cláusula de exceção para o caso do alarme de incêndio. ${ }^{253}$

Com efeito, Alexy defende que as regras devem ser sempre aplicadas através da subsunção, nunca através da ponderação, ainda que na hipótese de colisão entre direitos fundamentais expressos na forma de regras. Fazendo um acréscimo à teoria de Alexy, é certo que para solucionar o conflito entre regras também é possível a utilização de algum dos critérios de resolução de antinomias jurídicas (hierárquico, cronológico e especialidade ${ }^{254}$ ) ou ainda a

\footnotetext{
${ }^{251}$ Rel. Min. Cármen Lúcia. Julgamento em 24/06/2009.

${ }^{252}$ Dever decorrente da Convenção-Quadro sobre Controle do Uso do Tabaco, adotada pelos países membros da Organização Mundial de Saúde em 21 de maio de 2003, assinada pelo Brasil em 16 de junho de 2003, e promulgada através do Decreto n. 5.658 de 02 de janeiro de 2006.

253 ALEXY, Robert. Teoria dos Direitos Fundamentais. Op cit. p. 92.

${ }^{254}$ Alexy também propõe tal solução, ainda que sem tanto destaque: "Esse problema pode ser solucionado por meio de regras como lex posterior derogat legi priori e lex specialis derogat legi generali, mas é também possível
} 
aplicação de algumas das técnicas de interpretação constitucional (interpretação conforme a Constituição, nulidade parcial sem redução de texto ou declaração de inconstitucionalidade com redução de texto) ${ }^{255}$.

Já na hipótese de colisão entre direitos fundamentais expressos na forma de princípios, Alexy ${ }^{256}$ não entende que um deles possa ser declarado inválido, que seja possível introduzir em um deles uma cláusula de exceção ou mesmo que exista uma relação de precedência absoluta ou abstrata entre quaisquer princípios.

Com efeito, Alexy parte da técnica do sopesamento ou do balanceamento desenvolvida pela Corte Constitucional Alemã, para defender que todos os princípios abstratamente possuem a mesma importância, devendo, na hipótese de colisão entre eles, serem analisadas as condições fáticas e jurídicas do caso concreto para, ao final, decidir qual deve prevalecer.

A técnica do balanceamento, do sopesamento ou da ponderação foi desenvolvida pelo Tribunal Constituicional Alemão, tendo sido utilizada pela primeira vez em 1958, no caso Lüth $^{257}$, para resover um conflito entre direitos fundamentais.

Erich Lüth era o presidente do clube da imprensa de Hamburgo e convocou boicote aos filmes de Van Harlan, famoso diretor do cinema nazista, produzidos após 1945. Processado, Lüth foi condenado pelo Tribunal de Hamburgo, com base no artigo 826 do Código Civil Alemão, a omitir-se de novas convocações a favor do boicote, além do pagamento de multa pecuniária, considerando sua conduta contrária à moral e aos bons costumes. Incorformado, Lüth recorreu à Corte Constituional Alemã que, sopesando os direitos fundamentais em conflito, considerou a incitação ao boicote de Lüth protegida pela liberdade de expressão garantida na primeira seção do art. $5^{\circ}$ da Lei Fundamental Alemã, dando ganho de causa à Lüth.

Assim decidindo, o Tribunal Constitucional Alemão fixou 2 postulados seguidos até hoje:

1) Os direitos fundamentais previstos na Constituição irradiam seus efeitos por toda a legislação ordinária, ou seja, toda interpretação da ordem jurídica deve ser feita à luz da Carta

proceder de acordo com a importância de cada regra em conflito". ALEXY, Robert. Teoria dos Direitos Fundamentais. Op. cit. p. 93.

${ }^{255}$ Para um estudo mais profundo das técnicas de interpretação constitucional: STRECK, Lenio Luiz. Jurisdição constitucional e decisão jurídica. 3. ed. São Paulo: Editora Revista dos Tribunais, 2013. p. 746-802.

${ }^{256}$ ALEXY, Robert. Teoria dos Direitos Fundamentais. Op. cit. p. 93-99. Não obstante, na mesma obra Alexy ressalta que apenas excepcionalmente um princípio pode ser declarado inválido: "O princípio da segregação racional demonstra que também nos casos dos princípios é possível que a questão da validade seja postulada, embora isso raramente ocorra". p. 110.

${ }^{257}$ ALEXY, Robert. Direitos Fundamentais, Balanceamento e Racionalidade. Ratio Juris. Vol. 16, n.2, junho de 2003. p. 132-134. 
Magna, ainda que se trate de relações jurídicas entre particulares (eficácia horizontal dos direitos fundamentais constitucionais);

2) A ponderação é um método de solução para casos difíceis nos quais normas constitucionais com a estrutura de princípios entram em colisão.

Importante notar que, do resultado da colisão entre dois princípios, surgirá uma regra específica, a qual consistirá na consequência jurídica do princípio prevalecente, criada sempre com base nas condições fáticas do caso concreto. Alexy chama tal conexão de lei de colisão, sustentando, em outras palavras, que "as condições sob as quais um princípio tem precedência em face de outro constituem o suporte fático de uma regra que expressa a consequência jurídica do princípio que tem precedência." 258

Neste cenário, Alexy defende que "o procedimento para a solução de colisões de princípios é a ponderação" 259 , a qual deve ser aplicada a partir do princípio da proporcionalidade.

\section{PROPORCIONALIDADE}

Na linguagem cotidiana, proporcionalidade é igual à razoabilidade. Até na doutrina e na jurisprudência, normalmente a proporcionalidade é tratada como mero sinônimo de razoabilidade. Para muitos, a única diferença seria que a proporcionalidade seria uma construção dos alemães, enquanto a razoabilidade seria uma construção dos norteamericanos $^{260}$. Porém a razoabilidade e a proporcionalidade diferenciam-se na origem e na suas estruturas, senão vejamos.

Segundo o Professor Willis Santiago ${ }^{261}$, na Inglaterra não se fala em princípio da razoabilidade, mas sim em princípio da irrazoabilidade. Virgílio Afonso da Silva ${ }^{262}$, por sua vez, ensina que o princípio da irrazoabilidade, na forma como aplicada na Inglaterra, surgiu em decisão proferida em 1948 no caso Associated Provincial Pictures Houses Ltd. versus Wednesbury Corporation. Na verdade, em tal decisão foi formulado um teste de

\footnotetext{
${ }^{258}$ ALEXY, Robert. Teoria dos Direitos Fundamentais. Op. cit. p. 99.

${ }^{259}$ ALEXY, Robert. Colisão de direitos fundamentais e realização de direitos fundamentais no Estado de Direito Democrático. Op. cit. p. 75.

${ }^{260}$ BARROSO, Luis Roberto. Dez anos da Constituição de 1988 (foi bom pra você também?). Revista de Direito da Procuradoria-Geral do Estado do Rio de Janeiro, n. 52, 1999. p. 57.

${ }^{261}$ GUERRA FILHO, Willis Santiago. Princípio da proporcionalidade e teoria do direito. In: Grau, Eros Roberto / Guerra Filho, Willis Santiago (org.). Direito constitucional: estudos em homenagem a Paulo Bonavides. São Paulo: Malheiros, 2001. p. 283.

262 SILVA, Vírgilio Afonso da. O proporcional e o razoável. Revista dos Tribunais 798, 2002. p. $29 / 30$.
} 
irresponsabilidade (ou teste Wednesbury) segundo o qual "se uma decisão é de tal forma irrazoável, que nenhuma autoridade razoável a tomaria, então pode a Corte intervir". Sendo assim, tal critério serviria apenas para afastar atos absurdamente irrazoáveis, não se confundindo com a regra da proporcionalidade, conforme veremos.

Desta forma, não fica difícil concluir desde já que um ato pode ser razoável e desproporcional, já que para ele ser razoável basta que não seja absurdo.

Não obstante, o Poder Judiciário, incluindo o Supremo Tribunal Federal, geralmente usa os dois termos como sinônimos, sendo na verdade meros argumentos retóricos. O raciocínio costuma ser bem simples ${ }^{263}$ :

- a Constituição consagra a regra da proporcionalidade;

- o ato questionado não respeita essa exigência;

- o ato questionado é inconstitucional.

O conceito de proporcionalidade, como não poderia deixar de ser, não é unânime na doutrina.

Humberto Avila ${ }^{264}$ defende que o dever de proporcionalidade não é um princípio nem uma regra, sendo um postulado normativo aplicativo, ou seja, uma condição imposta pelo próprio Direito para que ele seja corretamente aplicado.

Virgílio Afonso da Silva, por sua vez, define a proporcionalidade como

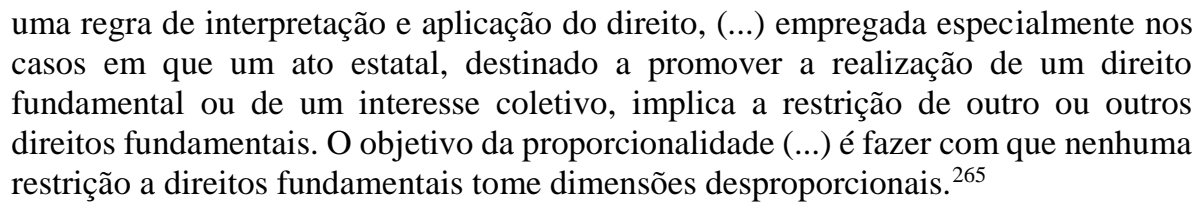

Outrossim, o mesmo autor elenca a existência de 3 (três) correntes em relação à estrutura do princípio da proporcionalidade ${ }^{266}$ :

1) Alexy: adequação, necessidade e proporcionalidade em sentido estrito;

2) Böckenförde e Schlink: adequação e necessidade;

3) Corte Européia de Direitos Humanos: adequação, necessidade, proporcionalidade em sentido estrito e legitimidade dos fins que a medida questionada pretende atingir.

\footnotetext{
${ }^{263}$ Idem. Ibidem. p. 31.

264 ÁVILA, Humberto. A distinção entre princípios e regras e a redefinição do dever de proporcionalidade. Op. cit. p. 24-25.

${ }^{265}$ SILVA, Vírgilio Afonso da. O proporcional e o razoável. Op. cit. p. 23.

${ }^{266}$ Idem. Ibidem. p. 35.
} 
Sem olvidar da importância das teorias acima, devido à limitação de tamanho e o propósito do presente artigo, vamos concentrar o estudo no conceito de proporcionalidade desenvolvida por Robert Alexy, majoritariamente aceito na doutrina e na jurisprudência pátrias.

Explicando a necessária conexão existente entre a sua teoria dos princípios e a aplicação da proporcionalidade, Robert Alexy sustenta o seguinte:

\begin{abstract}
Afirmar que a natureza dos princípios implica a máxima da proporcionalidade significa que a proporcionalidade, com suas três máximas parciais da adequação, da necessidade (mandamento do meio menos gravoso) e da proporcionalidade em sentido estrito (mandamento do sopesamento propriamente dito), decorre logicamente da natureza dos princípios, ou seja, que a proporcionalidade é deduzível dessa natureza. ${ }^{267}$
\end{abstract}

Assim sendo, importante destacar que a aplicação do princípio da proporcionalidade deve sempre seguir a ordem de seus 3 (três) subprincípios: adequação, necessidade e proporcionalidade em sentido estrito. Não obstante, importante destacar que a análise de determinada medida através de todos os subprincípios não é sempre obrigatória, ou seja, a relação entre eles é subsidiária, só se passando para o exame através do outro subprincípio caso o ato analisado seja considerado proporcional. Ex: eu só analiso se uma medida é necessária, após verificar se ela é adequada. Caso ela seja inadequada, ela já será tida como desproporcional, sendo prescindível o seu exame pelo subprincípio da necessidade.

O subprincípio da adequação consiste em realizar um exame absoluto, ou seja, sem comparações com outras hipóteses, em relação ao meio escolhido por determinado ato para alcançar seu objetivo. $\mathrm{O}$ ato deve ser considerado adequado se o meio escolhido por ele alcançar ou promover o objetivo pretendido, ou seja, tal medida só é inadequada se não contribuir em nada para o objetivo alcançado.

Podemos ter como exemplo uma lei que torna obrigatório o uso de capacete para todos motociclistas, com o objetivo de proteger a integridade física deles. O capacete é um meio abstratamente eficaz para o fim de proteger a integridade física do motociclista? Creio que sim. Logo, tal medida é adequada, devendo ser examinada através dos outros subprincípios da proporcionalidade para verificar se ela é, ao final, tida como proporcional.

O subprincípio da necessidade, por sua vez, obriga a realização de um exame comparativo, cotejando-se a gravidade do meio escolhido e o objetivo pretendido. A medida adotada deve ser considerada necessária se não existir outro meio menos gravoso para atingir o mesmo objetivo. Em suma, aqui pretende-se aferir se a realização de tal objetivo não pode ser promovido de outra maneira que limite menos o direito fundamental atingido. Assim, o

${ }^{267}$ ALEXY, Robert. Teoria dos Direitos Fundamentais. Op. cit. p. 117. 
primeiro passo é verificar qual é o direito que está sendo restringido e depois pensar em outras medidas tão eficazes quanto, porém menos gravosas, efetuando-se a comparação supramencionada.

Podemos aqui pensar, hipoteticamente, em uma lei que exija capacete para motoristas de automóvel, com o objetivo de proteger a integridade física deles. O direito fundamental restringido em tal hipótese seria a auto-determinação ou o direito à liberdade de escolha. Realizando o exame da necessidade, devemos indagar se o capacete é um meio abstratamente eficaz para o fim de proteger a integridade física dos motoristas. Novamente, creio que sim. Logo, tal medida seria adequada. Passando para o exame pelo subprincípio da necessidade, devemos perguntar se existiria outra medida, menos gravosa, para conseguir o mesmo objetivo. Como sabemos, o cinto de segurança é um meio mais eficaz do que o capacete para manter a integridade física dos motoristas de automóveis. Assim sendo, tal medida seria tida como desnecessária, e logo, desproporcional.

Por fim, o subprincípio da proporcionalidade em sentido estrito ou mandamento de ponderação é um exame que deve levar em conta a intensidade da restrição do direito atingido e a importância da realização do direito fundamental colidente. Em outros termos, trata-se de apontar qual direito, em determinado caso concreto, deve ser protegido: o direito atingido com a medida ou o direito que a medida quis prestigiar. Nas palavra de Alexy, o princípio da proporcionalidade em sentido estrito ou lei do sopesamento estabelece que "quanto maior o grau de não-satisfação ou de detrimento de um princípio, maior a importância de se satisfazer o outro". 268

A aplicação do subprincípio da proporcionalidade em sentido estrito deve ser dividida em 3 (três) fases. Primeiro deve ser determinada a intensidade da intervenção, ou seja, o grau de restrição ou de não-satisfação do direito atingido. Depois deve-se averiguar a importância das razões que justificam tal intervenção, ou seja, a importância de satisfazer o direito concorrente. Por fim, deve-se fazer a ponderação entre as respostas das 2 (duas) fases anteriores, concluindo se a importância de se satisfazer ou não o princípio concorrente justifica a restrição do direito atingido. Assim sendo, uma medida não passa neste teste se os motivos que fundamentarem a sua adoção não tenham peso suficiente para justificar a restrição ao direito fundamental atingido.

Vista a estrutura da proporcionalidade, é possível comprender a razão pela qual Alexy defende a sua obrigatória conexão com sua teoria dos princípios. Conforme já visto, o jurista

${ }^{268}$ ALEXY, Robert. Direitos Fundamentais, Balanceamento e Racionalidade. Op. cit. p. 136. 
alemão defende que princípios são mandamentos de otimização, ou seja, são normas jurídicas que determinam que algo seja realizado na maior medida possível, de acordo com as possibilidades fáticas e jurídicas do caso concreto. Conjugando tal conceito com a estrutura do princípio da proporcionalidade, podemos concluir que os subprincípios da adequação e da necessidade referem-se ao exame das possibilidades fáticas de realização de determinado princípio, enquanto o subprincípio da proporcionalidade em sentido estrito relaciona-se ao exame das possibilidades jurídicas da concretização do mesmo princípio.

Mas afinal, qual é o fundamento da proporcionalidade?

O Poder Judiciário, quando muito, fundamenta que o princípio da proporcionalidade é extraído do artigo $5^{\circ}$, LIV, da Carta Magna, ou seja, do chamado devido processo legal substantitvo (substantive due process of law) ${ }^{269}$.

Boa parte parte da doutrina pátria, bem como a doutrina e as decisões do Tribunal Constitucional da Alemanha, entendem que a regra da proporcionalidade tem seu fundamento no princípio do Estado de Direito. Tal entendimento, porém, não pode prevalecer, uma vez que diversos países desenvolvidos, onde inegavelmente já existia um Estado de Direito, não utilizavam ou não se utilizam da regra da proporcionalidade, como Inglaterra e Estados Unidos $^{270}$.

Segundo Vírgilio Afonso da Silva, "a exigibilidade da regra da proporcionalidade para a solução de colisões entre direitos fundamentais não decorre deste ou daquele dispositivo constitucional, mas da própria estrutura dos direitos fundamentais"271.

Com efeito, considerando-se que a maioria dos direitos fundamentais são configurados como princípios, ou seja, normas que obrigam que algo seja realizado na maior medida possível, de acordo com as possibilidades fáticas e jurídicas do caso (mandamentos de otimização), conclui-se que o princípio da proporcionalidade é exatamente a forma de efetuar o controle desse dever de otimização no caso concreto.

\footnotetext{
${ }^{269}$ A decisão da medida cautelar proferida na ADIN 1407-2 (DJ 24/11/2000), de relatoria do Ministro Celso de Mello, é um exemplo de tal entendimento: "O princípio da proporcionalidade - que extrai a sua justificação dogmática de diversas cláusulas constitucionais, notadamente daquela que veicula a garantia do substantive due process of law - acha-se vocacionado a inibir e a neutralizar os abusos do Poder Público no exercício de suas funções, qualificando-se como parâmetro de aferição da própria constitucionalidade material dos atos estatais. A norma estatal, que não veicula qualquer conteúdo de irrazoabilidade, presta obséquio ao postulado da proporcionalidade, ajustando-se à cláusula que consagra, em sua dimensão material, o princípio do substantive due process of law $\left(\mathrm{CF}\right.$, art. $5^{\circ}$, LIV)".

${ }^{270}$ SILVA, Luis Virgílio Afonso da. O proporcional e o razoável. Op. cit. p. 42-46. No mesmo sentido: ÁVILA, Humberto. A distinção entre princípios e regras e a redefinição do dever de proporcionalidade. Op. cit. p. 28.

${ }^{271}$ Idem. Ibidem. Op. cit. p. 45.
} 
Assim sendo, concluímos também que a regra da proporcionalidade é sempre cabível na hipótese de colisão entre direitos fundamentais previstos em forma de princípios, porém nunca quando tais direitos forem estruturados na forma de regras.

\section{CRÍTICAS À RACIONALIDADE DA PONDERAÇÃO}

Analisado o conteúdo da técnica da ponderação defendida por Robert Alexy, importante expor as críticas à sua utilização como forma de solução de colisão entre direitos fundamentais estruturados como princípios.

Sergio Nojiri, com base nas críticas do jurista espanhol Juan Antonio García Amado, sustenta que "a chamada ponderação não é mais que uma valoração, que pode ser tão aceitável ou inaceitável como seu oposto, pois não goza de uma vantagem epistêmica, mas apenas prática: ela é somente a valoração preferida pelo Tribunal"272.

Carlos Bernal Pulido ${ }^{273}$, por sua vez, elenca 3 (três) críticas doutrinárias ao uso da ponderação:

1) Indeterminação da ponderação: não existem critérios jurídicos que garantam a objetividade da ponderação, que sejam vinculantes ao juiz. Logo, a ponderação seria mero subjetivismo do juiz;

2) Incomensurabilidade (impossibilidade de medição) da ponderação: não é possível comparar duas coisas que, devido a suas diferenças radicais, não são comparáveis. Tal crítica advém do fato de que em uma sociedade pluralista não pode existir hierarquia entre princípios, o que refletiria em uma pré-definição de uma hierarquia entre os valores existentes na sociedade;

3) Impossibilidade de prever os resultados da ponderação: a ponderação sacrifica a segurança jurídica uma vez que todos os resultados da ponderação são particulares, dependendo de circunstâncias de cada caso e não de critérios gerais.

Respondendo a tais críticas, o mesmo Carlos Bernal Pulid ${ }^{274}$ sustenta, primeiramente, que toda busca de hiperracionalidade também é irracional. Ademais, a subsunção, bem como a

\footnotetext{
272 NOJIRI, Sergio. Neoconstitucionalismo versus democracia: um olhar positista. Curitiba: Juruá, 2012. p. 285. ${ }^{273}$ PULIDO, Carlos Bernal. La racionalidad de la ponderación. In "El principio de proporcionalidad en el Estado constitucional". Miguel Carbonell (Coordenador). Universidad Externado de Colombia. p. 51-55. ${ }^{274}$ Idem. Ibidem. p. 56-62.
} 
ponderação, não fica a salvo de subjetivismos do juiz, já que também depende da interpretação da norma. No entanto, ninguém diz que a subsunção é irracional.

Com efeito, a objetividade é um ideal inalcançável em qualquer ordenamento jurídico, principalmente em relação a princípios. Ademais, a indeterminação inerente aos princípios é fundamental na manutenção do texto normativo e a evolução de sua concretização de acordo com o momento político, social e jurídico vivido, evitando a necessidade de constantes reformas constitucionais.

Uma interpretação racional a respeito da colisão entre direitos fundamentais deve possuir termos claros e consistentes, além de premissas completas, observando as regras da lógica, da argumentação e da coerência. Desta forma, ainda que não acreditemos que seja possível assegurar que a utilização da técnica da ponderação conduzirá sempre a uma mesma resposta, é certo que a demonstração da aplicação completa do princípio da proporcionalidade e de seus subprincípios servem para justificar a posição tomada pelo intérprete, o que já torna a sua aplicação recomendável. Com efeito, é salutar que tal expediente seja sempre adotado pelo Poder Judiciário, como forma de possibilitar o controle social das suas decisões, legitimando-as.

Nas palavras de Carlos Bernal Pulido,

La ponderación representa un procedimiento claro, incluso respecto de sus proprios límites. Si bien no puede reducir la subjetividad del intérprete, en ella sí puede fijarse, cuál es el espacio en donde yace esta subjetividad, cuál es el margen para las valoracionaes del juez y cómo dichas valoraciones constituyen también un elemento para fundamentar las decisiones. La ponderación se rige por ciertas reglas que admiten una aplicácion racional, pero que de ninguna manera pueden reducir la influencia de la subjetividad del juez en la decisión y su fundamentación ${ }^{275}$.

Assim sendo, podemos concluir que a ponderação pode ser tanto racional como irracional. Na poderação racional a fundamentação deve expor todos os argumentos a favor e contra a medida tomada, explicitando as razões pelas quais não foram adotados os argumentos contra a interpretação tomada. Por outro lado a ponderação será irracional quando realizada exclusivamente com base nas convicções do intérprete, sem a demonstração completa do raciocínio jurídico aplicado ao caso concreto, servindo apenas como tentativa de fundamentação ou legitimação da decisão tomada.

275 PULIDO, Carlos Bernal. Estructura y límites de la ponderación. In "Doxa: Cuadernos del Filosofía del Derecho, núm. 26 (2003). Universidad del Alicante. p. 29. 


\section{CONSIDERAÇÕES FINAIS}

Conforme demonstrado, o grande número de direitos fundamentais previstos na Constituição Federal faz com que eles entrem constantemente em colisão, exigindo-se do aplicador do direito a escolha de qual direito deve prevalecer no caso concreto.

Ocorre que, por mais que a doutrina desenvolva teorias a respeito da solução para as colisões entre direitos fundamentais, é certo que todo texto constitucional ou legal deve ser interpretado antes de ser aplicado, extraindo-se dele diferentes normas, de forma que sempre haverá a possibilidade de existirem decisões diferentes a respeito de um mesma situação.

Sendo assim, procurou-se demonstrar no presente artigo a importância da teoria de Robert Alexy para solução da colisão entre direitos fundamentais, sem a pretensão de esgotar a matéria e sem a pretensão de demonstrar que tal teoria é a única maneira de tratar do assunto.

Com efeito, a grande valia da aplicação da ponderação e do princípio da proporcionalidade, como forma de solucionar conflitos entre direitos fundamentais estruturados como princípios, é conferir alguma racionalidade à escolha de qual direito deve prevalecer no caso concreto, sem que tal escolha seja feita de forma arbitrária ou de acordo exclusivamente com o interesse do julgador.

Considerando que vivemos numa sociedade democrática e pluralista, não podemos esperar que todos aplicadores do direito interpretem um conflito de direitos fundamentais sempre da mesma maneira, mas podemos exigir, pelo menos, que eles demonstrem o seu raciocínio, de forma a dar transparência e possibilitar que haja posterior avaliação e controle por parte de toda sociedade e dos Poderes constituídos.

\section{REFERÊNCIAS}

ALEXY, Robert. Colisão de direitos fundamentais e realização de direitos fundamentais no Estado de Direito Democrático. Revista de Direito Administrativo, Rio de Janeiro, v. 217, 2015. Disponível em <http://bibliotecadigital.fgv.br/ojs/index.php/rda/article/view/47414/4 5316>. Acesso em: 01 de julho de 2016.

Direitos Fundamentais, Balanceamento e Racionalidade. Ratio Juris. Vol. 16, n. 2, 2003. Disponível em <http://docslide.com.br/documents/robert-alexy-direitos-fundamentaisbalanceamento-e-racionalidadepdf.html>. Acesso em: 01 de julho de 2016.

Teoria dos Direitos Fundamentais. Tradução de Vírgilio Afonso da Silva. 2 ed. São Paulo: Malheiros Editores, 2014. 
ÁVILA, Humberto. A distinção entre princípios e regras e a redefinição do dever de proporcionalidade. Revista Diálogo Jurídico, Salvador, CAJ - Centro de Atualização Jurídica, v. I, n ${ }^{\circ} .4$, julho, 2001. Disponível em: < http://www.direitopublico.com.br/pdf_4/DIALOGOJURIDICO-04-JULHO-2001-HUMBERTO-AVILA.pdf >. Acesso em: 09 de julho de 2016.

NEOCONSTITUCIONALISMO: ENTRE A "CIÊNCIA DO DIREITO" E O "DIREITO DA CIENCIA". Revista Eletrônica de Direito Do Estado (REDE), Salvador, Instituto Brasileiro de Direito Público, n. 17, janeiro/fevereiro/março, 2009. Disponível em: $<$ http://revistas.unifacs.br/index.php/redu/article/viewFile/836/595>. Acesso em: 10 de julho de 2016.

BÄCKER, Carsten. Regras, princípios e derrotabilidade. Revista Brasileira de Estudos Políticos n. ${ }^{\circ}$ 102, 2011. Disponível em: <http://www.pos.direito.ufmg.br/rbepdocs/102 055082.pdf >. Acesso em: 01 de julho de 2016.

BARROSO, Luis Roberto. Dez anos da Constituição de 1988 (foi bom pra você também?). Revista de Direito da Procuradoria-Geral do Estado do Rio de Janeiro, n. 52, 1999. Disponível em: $\quad$ http://www. http://download.rj.gov.br/documentos/10112/813727/DLFE47868.pdf/Revista52Doutrina_pg_36_a_65.pdfr>. Acesso em: 13 de julho de 2016.

DWORKIN, Ronald. Levando os direitos a sério. Trad. Nelson Boeira. 3. ed. São Paulo: Editora WMF Martins Fontes, 2010.

GUERRA FILHO, Willis Santiago. Processo Constitucional e Direitos Fundamentais. 4. ed. São Paulo: RCS, 2007.

. Princípio da proporcionalidade e teoria do direito. In: Grau, Eros Roberto / Guerra Filho, Willis Santiago (org.). Direito constitucional: estudos em homenagem a Paulo Bonavides. São Paulo: Malheiros, 2001.

HÄRBELE, Peter. Hermenêutica Constitucional - A Sociedade Aberta dos Intérpretes da Constituição: contribuição para a interpretação pluralista e procedimental da Constituição. Tradução e apresentação de Gilmar Ferreira Mendes. Sergio Antonio Fabris Editor. Porto Alegre/RS, 1997.

NOJIRI, Sergio. Neoconstitucionalismo versus democracia: um olhar positista. Curitiba: Editora Juruá, 2012.

NUNES JUNIOR, Vidal Serrano. A cidadania social na Constituição de 1988. - Estratégias de Positivação e Exigibilidade Judicial dos Direitos Sociais. São Paulo: Editora Verbatim, 2009. 
PULIDO, Carlos Bernal. La racionalidad de la ponderación. In "El principio de proporcionalidad en el Estado constitucional". Miguel Carbonell (Coordenador). Universidad Externado de Colombia.

Estructura y límites de la ponderación. In "Doxa: Cuadernos del Filosofía del Derecho, núm. 26 (2003). Universidad del Alicante.

SILVA, Virgílio Afonso da. O proporcional e o razoável. Revista dos Tribunais 798, 2002. Disponível em: <http://www.revistas.unifacs.br/index.php/redu/article/viewFile/1495/1179>. Acesso em: 01 de julho de 2016.

Princípios e regras: mitos e equívocos acerca de uma distinção. Revista LatinoAmericana de Estudos Constitucionais I, 2003. Disponível em: <http://constituicao.direito.usp.br/wp-content/uploads/2003-RLAEC01-Principios_e_regras. pdf >. Acesso em: 01 de julho de 2016.

\title{
FUNDAMENTAL RIGHTS BUMP, CONSIDERATION AND PROPORTION IN ROBERT ALEXY VISION
}

\begin{abstract}
This article is part of the problem related to the collision of fundamental rights, which became mandatory study in Brazil after the promulgation of the Constitution of 1988. Indeed, our Constitution has shaped many fundamental rights in your body, making it difficult to life of his interpreter in the face of constant situations in which two or more rights conflict. In this context, the concept of principle developed by Robert Alexy and his theory that the collision between fundamental rights, when structured as principles, should be solved with the application of the weighting of the technique by the principle of proportionality, are highlighted in national legal scene. Nevertheless, it notes that the application of his theory by the Judiciary not rarely generates decisionismos and legal uncertainty, encouraging the writing of this article to contribute to a better understanding of the lessons of Robert Alexy and consequently greater clarity in the application considering and proportionality.
\end{abstract}

Keywords: Fundamental rights. Collision. Weighting. Proportionality. 